\title{
Application of Single-Server Queue System in Performance Analysis of Shuttle Bus Operation: A Case Study of Federal University of Technology Akure
}

\author{
Kanyio Olufunto Adedotun \\ Department of Transport Management Technology \\ The Federal University of Technology,Akure \\ Ondo State, Nigeria \\ E-mail: oobembe97@gmail.com
}

\begin{abstract}
This study has examined the performance of University transport bus shuttle based on utilization using a Single-server queue system which occur if arrival and service rate is Poisson distributed (single queue) (M/M/I) queue. In the methodology, Singleserver queue system was modelled based on Poisson Process with the introduction of Laplace Transform. Also, PASTA was introduced in queuing systems with Poisson arrivals. It is concluded that the performance of University transport bus shuttle is 93 percent which indicates a very good performance such that the supply of shuttle bus in FUTA is capable of meeting the demand. This study can be improved upon by examining the peak and off-peak period of traffic in the two major corridors (North gate and South gate) of FUTA, the economic cost of operating bus shuttle services can also be examined.
\end{abstract}

Keywords: Single-Server Queue System; Transit Shuttle Buses; FUTA

\section{I.Introduction}

The issues arising from transportation has continually subjected to various debates in the urban societies. Globally, several attempts have been made to tackle the challenges, although the situation is not getting much better (Aderamo, 20I2; Adanikin, Olutaiwo, and Obafemi, 2017; Sidiq, 2019). Managing transport infrastructures is crucial to facilitate accessible, affordable, reliable, safe, and efficient that movement of people and goods, which can be achieved by continous assessment of transport performance indicators. Among the various modes of transport, the road transport is highly predominant which offers door-todoor service as in the case of the Federal University of Technology Akure (FUTA). Road transport infrastructure in the University is commonly plied by shuttle buses for the movement of the students, staff, members and non-members of the Institution to and from the University on a daily basis.

Among the noticeable transportation problems in the University are traffic congestion; longer commuting; public transport inadequacy; difficulties for tricycles to have access to routes being plied by shuttle buses, challenge of freight distribution from one end of the University to another end, and other challenges which all impacts the performance of the University transport shuttle. This study concentrates on the performance of University transport bus shuttle with the aim of examining the bus shuttle efficiency based on utilization.

Adeniran and Kanyio (2019) have laid a foundation of model on single-server queue system which this study will absolutely rely on. A similar study was conducted by Adanikin, Olutaiwo, and Obafemi (2017) on the performance study of University of Ado Ekiti (UNAD) transit shuttle buses. They adopted traffic volume, speed, density and revenue as main parameters of performance of transport shuttles, and find that the morning peak period (8.00am to 9.00am) has 234 vehicles $/ \mathrm{hr}$, evening peak period $(2.00 \mathrm{pm}$ to $3.00 \mathrm{pm}$ ) has 284 vehicles $/ \mathrm{hr}$, while the off-peak period (II.00am to I2.00pm) has I56 vehicles/hr. Also, The average stopping time was 6.55 minutes, average interval between arrivals of motorists was I6.40 seconds, the average queue length was I4.23 people, and the average waiting time at the bus-stop 4.17 minutes. These values were obtained using the queuing theory and shows much commuters time is lost on transit queues. This study focuses on the performance of bus terminal in FUTA, and does not factor in other parameters such as peak period, traffic volume, traffic speed, density, and others.

A very close study was examined by Sidiq (2019) on single-server queue system of shuttle bus performance in the Federal University of Technology Akure. In his study, Single server queue system was modelled based on Poisson Process with the introduction of Laplace Transform which was culled from Adeniran and Kanyio (2019). The study finds that the performance of University transport bus shuttle is 96.6 percent which indicates a very good performance such that the supply of 
shuttle bus in FUTA is capable of meeting the demand. This present study was conducted barely two weeks after the study of Sidiq was conducted, and will replicate the methodology of Sidiq as culled from Adeniran and Kanyio (2019).

\section{Methodology \\ 2.I Concept of Queuing}

The concept of queue was first used for the analysis of telephone call traffic in I9I3 (Copper, I98I; Gross and Harris, I985; Bastani, 2009). In a system that deals with the rate of arrival and service rate, waiting time is inevitable and it is always influenced by queue length. It is therefore crucial to minimize the waiting time to the lowest level in the bus terminal (Jain, Mohanty and Bohm, 2007). This is referred to as queuing system (Adeniran and Kanyio, 2019).

The basic application of queue is shown in Figure I, also the basic quantities are:

i. Number of customers in queue L (for length);

ii. Time spent in queue $\mathrm{W}$ for (wait)

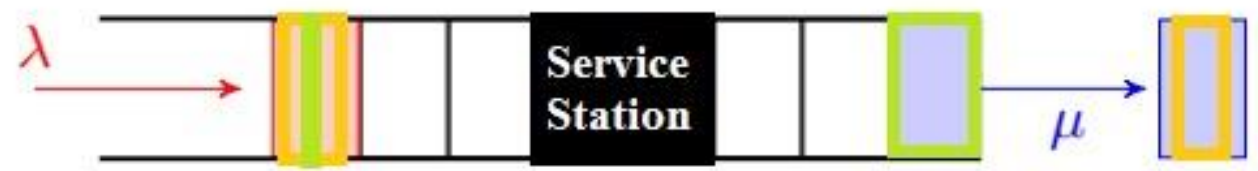

Figure I: Basic application of queue

Source: Adeniran and Kanyio (2019)

Examples of queue system are:

I. Single-server queue system: This is also referred to as single queue, single server. It is simple if arrivals and services are Poisson distributed (M/M/I) queue. It has limited number of spots and not difficult. Figure 2 depicts single-server queue system.

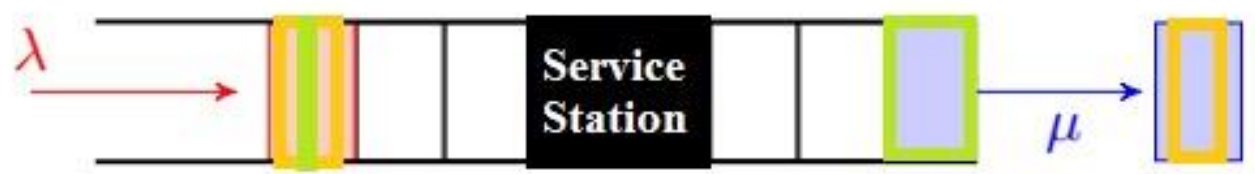

Figure 2: Single-server queue system

Source: Adeniran and Kanyio (2019)

2. Multi-server queue system: This is comprises of single queue, many servers $(\mathrm{M} / \mathrm{M} / \mathrm{c})$ queue. The $\mathrm{c}$ is referred to as Poisson servers. Figure 3 depicts multiple-server queue system.

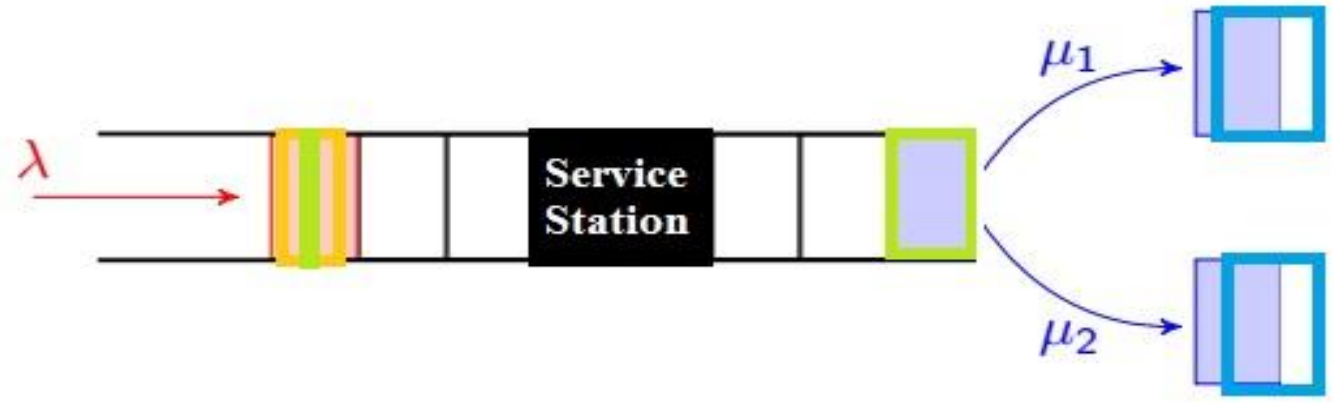

Figure 3: Multiple-server queue system

Source: Adeniran and Kanyio (2019) 
In single-server queue system, arrival and service processes are Poisson such that

a. Customers arrive at an average rate of $\lambda$ per unit time;

b. Customers are serviced at an average rate of $\mu$ per unit time;

c. Interarrival and inter-service time are exponential and independent;

d. Hypothesis of Poisson arrivals is reasonable; and

e. Hypothesis of exponential service times are not so reasonable (Adeniran and Kanyio, 2019)

In order to explain how the queuing system works, there is need to first introduce the Poisson Process (PP). It has exceptional properties and is a very important process in queuing theory. To simplify the model, we often assume customer arrivals follow a PP. The Laplace Transform (LT) is also a very powerful tool that was adopted in the analysis (Trani, 20II). Apart from PP and LT, there is focus on the queue model itself (Adeniran and Kanyio, 2019).

\subsection{Modelling of Single Queue System}

\subsection{Queuing system from Poisson Process and "PASTA"}

The Poisson Process (PP) is important in queue theory due to its outstanding properties. According to Adan and Resing (2015), queuing system is achieved as "let $N(t)$ be the number of arrivals in $[0, t]$ for a PP with rate $\lambda$, i.e. the time between successive arrivals is exponentially distributed with parameter $\lambda$ and independent of the past. Then $N(t)$ has a Poisson distribution with parameter $\lambda t$. This is culled from Adeniran and Kanyio (2019).

$\mathrm{P}(\mathrm{N}(\mathrm{t})=\mathrm{k})=\frac{(\lambda \mathrm{t})^{\mathrm{k}}}{\mathrm{k} !} \mathrm{e}^{-\lambda t}$, for $\mathrm{k}=0, \mathrm{I}$, Equation I

The mean, and coefficient of variation of $\mathrm{N}(\mathrm{t})$ are

Mean: $\mathrm{E}(\mathrm{N}(\mathrm{t}))=\lambda \mathrm{t}$

Coefficient of Variation: $\mathrm{c}^{2} \mathrm{~N}(\mathrm{t})=\frac{1}{\lambda \mathrm{t}}$. Equation 2

By the memoryless property of Poisson distribution, it can be verified that

$\mathrm{P}($ arrival in $(\mathrm{t}, \mathrm{t}+\Delta \mathrm{t}])=\lambda \Delta \mathrm{t}+\mathrm{O}(\Delta \mathrm{t})$ Equation 3

Hence, when $\Delta \mathrm{t}$ is small,

$\mathrm{P}(\operatorname{arrival}$ in $(\mathrm{t}, \mathrm{t}+\Delta \mathrm{t})) \approx \lambda \Delta \mathrm{t}$ Equation 4

In each small time interval of length $\Delta$ t the occurrence of an arrival is equally likely. In other words, Poisson arrivals occur completely randomly in time. The Poisson Process is an extremely useful process for modelling purposes in many practical applications. An important property of the Poisson Process is called "PASTA" (Poisson Arrivals See Time Averages).

PASTA is meant for queuing systems with Poisson arrivals, (M/./. systems), arriving vehicles find on average the same situation in the queuing system as an outside observer looking at the system at an arbitrary point in time. More precisely, the fraction of vehicles finding on arrival the system in some state $A$ is exactly the same as the fraction of time the system is in state $A$.

\subsubsection{Laplace Transform}

The Laplace transform $\mathrm{Lx}(\mathrm{s})$ of a nonnegative random variable $\mathrm{X}$ with distribution function $\mathrm{f}(\mathrm{x})$ is define as: $\mathrm{Lx}(\mathrm{s})=\mathrm{E}\left(\mathrm{e}^{-\mathrm{s} X}\right)=\int_{\mathrm{x}=0}^{\infty} \mathrm{e}^{-\mathrm{sX}} \mathrm{f}(\mathrm{x}) \mathrm{dx}$ Equation 5

It can be noted that

$\mathrm{Lx}(0)=E\left(e^{-x .0}\right)=E(I)=I$ Equation 6

and

$$
\begin{aligned}
\mathrm{L}^{\mathrm{I}} \mathrm{x}(0)= & \mathrm{E}\left(\left(\mathrm{e}^{-\mathrm{sX}}\right)^{\mathrm{I}}\right) \mid \mathrm{s}=0 \\
& =\mathrm{E}\left(-\mathrm{Xe}^{-\mathrm{sX}}\right) \mid \mathrm{s}=0
\end{aligned}
$$




$$
=-\mathrm{E}(\mathrm{X}) \ldots \ldots \ldots \ldots \ldots \ldots \text { Equation } 7
$$

Correspondingly,

$\mathrm{L}_{\mathrm{x}}^{(\mathrm{k})}(0)=(-\mathrm{I})^{\mathrm{k}} \mathrm{E}\left(\mathrm{X}^{\mathrm{k}}\right) \ldots \ldots \ldots \ldots \ldots \ldots$ Equation 8

There are many useful properties of Laplace Transform. These properties can make calculations easier when dealing with probability. For instance, let X, Y, Z be three random variables with

$\mathrm{Z}=\mathrm{X}+\mathrm{Y}$ and $\mathrm{X}, \mathrm{Y}$ are independent.

Then the Laplace Transform of $Z$ can be found as:

$\mathrm{Lz}(\mathrm{s})=\mathrm{Lx}(\mathrm{s}) \cdot \operatorname{Ly}(\mathrm{s}) \ldots \ldots \ldots \ldots \ldots \ldots$ Equation 9

Moreover, when $\mathrm{Z}$ with probability $\mathrm{P}$ equals $\mathrm{X}$, with probability I - P equals $\mathrm{Y}$, then

$\operatorname{Lz}(\mathrm{s})=\operatorname{PLx}(\mathrm{s})+(\mathrm{I}-\mathrm{P}) \operatorname{Lr}(\mathrm{s}) \ldots \ldots \ldots \ldots \ldots$ Equation IO

Laplace Transforms of some useful distributions can now be introduced.

a. Suppose $\mathrm{X}$ is a random variable which follows an exponential distribution with rate $\lambda$. The Laplace Transform of $\mathrm{X}$ is Lx $(\mathrm{s})=\frac{(\lambda)}{\lambda+\mathrm{s}} \ldots \ldots \ldots \ldots \ldots \ldots$ Equation $I I$

b. Suppose $\mathrm{X}$ is a random variable which follows an Erlang $-\mathrm{r}$ distribution with rate $\lambda$. Then $\mathrm{X}$ can be written as:

$\mathrm{X}=\mathrm{X}_{\mathrm{I}}+\mathrm{X}_{2}+\cdots+\mathrm{X}$ Equation 12

where $X_{i}$ are i.i.d. exponential with rate $\lambda$. Therefore, we have

$\mathrm{LX}(\mathrm{s})=\mathrm{LX}_{\mathrm{I}}(\mathrm{s}) \cdot \mathrm{LX}_{2}(\mathrm{~s}) \ldots \mathrm{LX}_{\mathrm{r}}(\mathrm{s})$

$$
=\left(\frac{\lambda}{\lambda+\mathrm{s}}\right)^{\mathrm{n}} \ldots \ldots \ldots \ldots \ldots \ldots \text { Equation } \mathrm{I3}
$$

c. Suppose $\mathrm{X}$ is a constant real number $\mathrm{c}$, then

$$
\begin{aligned}
\operatorname{Lx}(s)= & E\left(e^{-s X}\right) \\
& =E\left(e^{-s c}\right) \\
& =e^{-s c} \quad \ldots
\end{aligned}
$$

Equation I4 (culled from Adeniran and Kanyio, 2019)

\subsubsection{Basic queuing systems}

Kendall's notation shall be used to describe a queuing system as denoted by:

$\mathrm{A} / \mathrm{B} / \mathrm{m} / \mathrm{K} / \mathrm{n} / \mathrm{D}$ Equation I5 (Adan and Resing, 2016)

Where

A: distribution of the interarrival times

B: distribution of the service times

$\mathrm{m}$ : number of servers

serviced

$\mathrm{K}$ : capacity of the system, the maximum number of passengers in the system including the one being

n: population size of sources of passengers

D: service discipline

G shall be used to denote general distribution, $M$ used for exponential distribution ( $M$ stands for Memoryless), D be used for deterministic times (Sztrik, 2016).

$\mathrm{A} / \mathrm{B} / \mathrm{m}$ is also used to describe a queuing system, where:

A stands for distribution of interarrival times,

$B$ stands for distribution of service times and

$\mathrm{m}$ stands for number of servers.

Hence $\mathrm{M} / \mathrm{M} / \mathrm{I}$ denotes a system with Poisson arrivals, exponentially distributed service times and a single server.

$\mathrm{M} / \mathrm{G} / \mathrm{m}$ denotes an $\mathrm{m}$ - server system with Poisson arrivals and generally distributed service times, and so on.

In this section, the basic queuing models $(\mathrm{M} / \mathrm{M} / \mathrm{I}$ system), which is a system with Poisson arrivals, exponentially distributed service times and a single server. The following part is retrieved from Queuing Systems (Adan and Resing, 2016).

Firstly, it is assumed that inter-arrivals follows an exponential distribution with rate $\lambda$, and service time follows the exponential distribution with rate $\mu$. Further, in the single service model, to avoid queue length instability, it is assume that: According to Adanikin, Olutaiwo and Obafemi (2017), 
Utilization $(\mathrm{R})=\frac{\text { Average Arrival Rate }(\lambda)}{\text { Average service rate }(\mu)}<\mathrm{I}$ Equation 16

Here $\mathrm{R}$ is the fraction of time the server is working (called the utility factor). Time-dependent behaviour of this system will be considered firstly, then the limiting behaviour. Let $R_{n}(t)$ denote the probability that at time $t$ there are $n$ passengers in the system.

Then by equation 3 , when $\Delta \mathrm{t} \rightarrow 0$,

$\mathrm{R}_{0}(\mathrm{t}+\Delta \mathrm{t})=(\mathrm{I}-\lambda \Delta \mathrm{t}) \mathrm{R}_{0}(\mathrm{t})+\mu \Delta \mathrm{t} \mathrm{R}_{\mathrm{I}}(\mathrm{t})+\mathrm{o}_{\mathrm{o}}(\Delta \mathrm{t})$ Equation I7

$\mathrm{R}_{\mathrm{n}}(\mathrm{t}+\Delta \mathrm{t})=\lambda \Delta \mathrm{t} \mathrm{R}_{\mathrm{n}-\mathrm{I}}(\mathrm{t})+(\mathrm{I}-(\lambda+\mu) \Delta \mathrm{t}) \mathrm{R}_{\mathrm{n}}(\mathrm{t})+\mu \Delta \mathrm{t} \mathrm{R}_{\mathrm{n}+\mathrm{I}}(\mathrm{t})+{ }_{0}(\Delta \mathrm{t})$ Equation I8

where $\mathrm{n}=\mathrm{I}, 2, \ldots$

Hence, by tending $\Delta t \rightarrow 0$, the following infinite set of differential equations for $R_{n}(t)$ will be obtained. $\mathrm{R}^{\mathrm{I}_{0}}(\mathrm{t})=-\lambda \mathrm{R}_{0}(\mathrm{t})+\mu \mathrm{R}_{\mathrm{I}}(\mathrm{t})$ Equation 19

$R^{I}{ }_{n}(t)=\lambda_{p_{n-I}(t)}-(\lambda+\mu) R_{n}(t)+\mu R_{n+I}(t), n=I, 2$, Equation 20

It is very difficult to solve these differential equations. However, when we focus on the limiting or equilibrium behaviour of this system, it is much easier.

It was revealed by (Sztrik, 20I6) that when $t \rightarrow \infty, R_{n}(t) \rightarrow 0$ and $R_{n}(t) \rightarrow R_{n}$. It follows that the limiting probabilities $R_{n}$ satisfy equations

$0=-\lambda R_{0}+\mu R_{1}$

$0=\lambda R_{n-1}-(\lambda+\mu) R_{n}+\mu R_{n+1},, n=I, 2$,

Moreover, $\mathrm{R}_{\mathrm{n}}$ also satisfy

$\sum_{\mathrm{n}=0}^{\infty} \mathrm{Rn}=1$

Equation 23

which is called the normalization equation. We can also use a flow diagram to derive the normalization equations directly. For an $\mathrm{M} / \mathrm{M} / \mathrm{I}$ system, the flow diagram is shown in figure 4 :

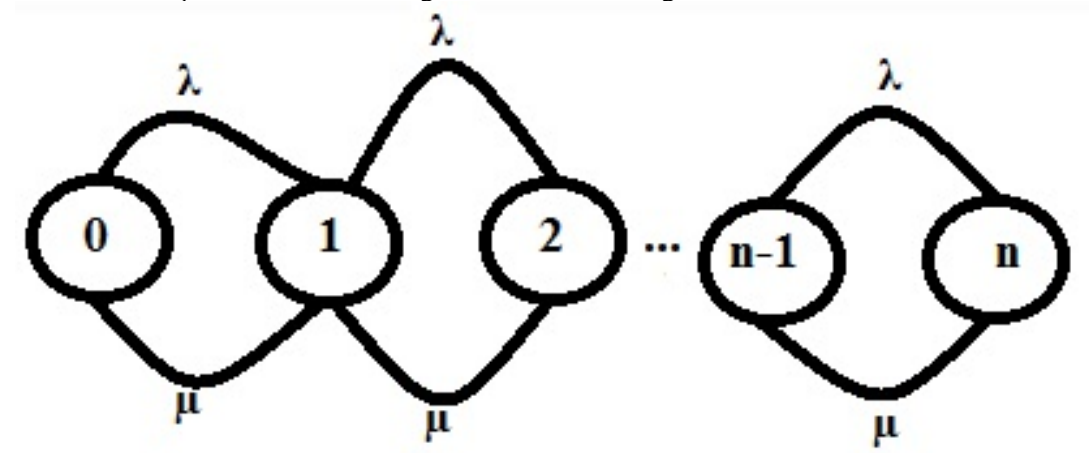

Figure 4: Process diagram for M/M/I Queue, $\mathrm{k}=\mathrm{I}, 2,3, \ldots$ (Ademoh and Anosike, 20I4; Adeniran and Kanyio, 2019) The rate matrix of the system is:

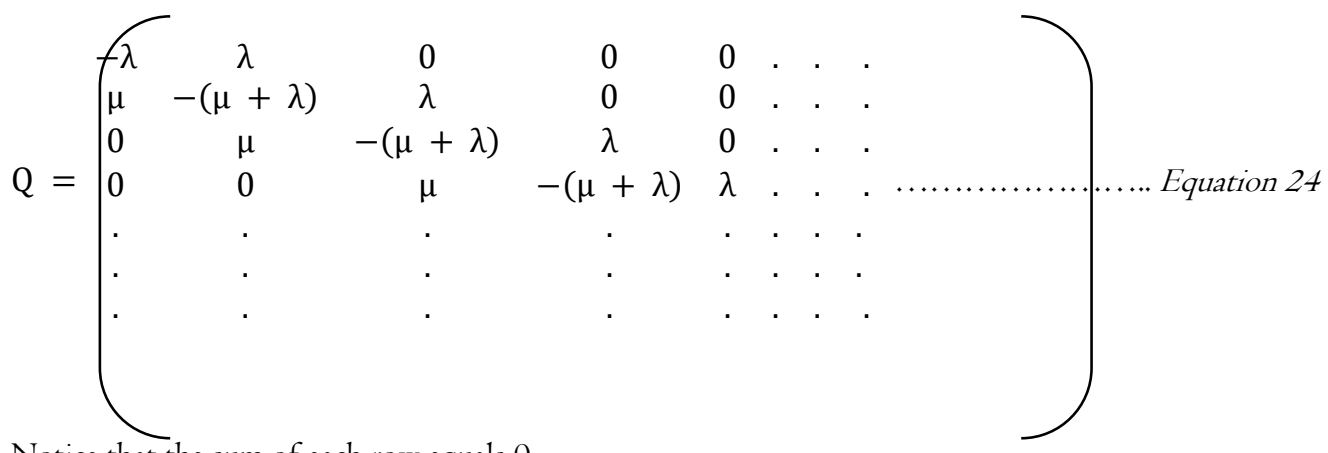

Notice that the sum of each row equals 0 .

In order to determine the equations from the flow diagram, a global balance principle was adopted. Global balance principle states that for each set of states under the equilibrium condition, the flow out of set is equal to the flow into that set. Based on figure I, 


$$
\left(\begin{array}{cccc}
\text { State } & \text { Rate In } & = & \text { Rate Out } \\
0 & \mu R 1 & = & \lambda R 0 \\
1 & \lambda R 0+\mu R 2 & = & (\lambda+\mu) R 1 \\
2 & \lambda R 1+\mu R 3 & = & (\lambda+\mu) R 2
\end{array}\right)
$$

This is exactly the normalization equation. To solve the equation, firstly, it was assume that $(R)=\frac{\text { Average Arrival Rate }(\lambda)}{\text { Average service rate }(\mu)}$ which is known as the utilization factor. From the equilibrium equation of state 0 , we have:

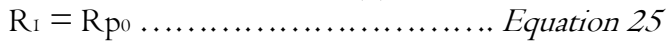

When equation 25 was substituted into the equilibrium equation of state $I$, then:

$\lambda \mathrm{p}_{0}+\mu \mathrm{p}_{2}=(\lambda+\mu) \mathrm{R}_{0}$

$$
=\frac{\lambda^{2}}{\mu} \mathrm{po}
$$

That is

$\mu \mathrm{p}_{2}=\frac{\lambda^{2}}{\mu} \mathrm{p}_{0}$ Equation 27

Therefore,

Generally,

$$
\mathrm{p}^{2}=\mathrm{R}^{2} \mathrm{p}_{0} \ldots \ldots \ldots \ldots \ldots \ldots \ldots \ldots \ldots \text { Equation } 28
$$

Since

$$
\mathrm{pk}=\mathrm{R}^{\mathrm{k}} \mathrm{p}_{0} \ldots \ldots \ldots \ldots \ldots \ldots \ldots \ldots \ldots \text { Equation } 29
$$

$\sum_{n=0}^{\infty} \quad \mathrm{p}_{\mathrm{n}}=\mathrm{I}$ Equation 30

Using (I.29), we can replace pk by Ro. Then

$\sum_{n=0}^{\infty} \quad \mathrm{R}^{\mathrm{n}} \mathrm{p}_{0}=\mathrm{I}$ Equation 31

That is

$\frac{1}{1-R} \mathrm{p}_{0}=\mathrm{I}$

po $=\mathrm{I}-\mathrm{R}$

Moreover, for any $\mathrm{k}$

$\mathrm{pk}_{\mathrm{k}}=\mathrm{R}^{\mathrm{k}}(\mathrm{I}-\mathrm{R})$

Equation 32

Finally is the limiting probability $\mathrm{pk}$ in the $\mathrm{M} / \mathrm{M} / \mathrm{I}$ system. The expected queue length $\mathrm{L}$ is given by

$$
\begin{aligned}
& E(L)=\sum_{i=0}^{\infty} \text { i. pi } \\
& =\sum_{i=0}^{\infty} i \cdot R^{i}(1-R) \\
& =\mathrm{R}(1-\mathrm{R}) \sum_{\mathrm{i}=0}^{\infty} \mathrm{i} \cdot \mathrm{R}^{\mathrm{i}} \\
& =R(1-R)\left(\sum_{i=1}^{\infty}\left(i \cdot R^{i}\right)^{i}\right) \\
& =\mathrm{R}(\mathrm{I}-\mathrm{R})\left(\frac{1}{1-\mathrm{R}}\right)
\end{aligned}
$$

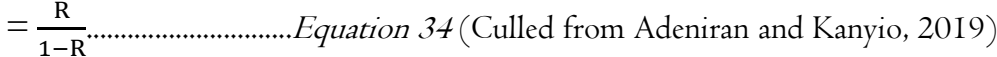

\section{Results and Discussion}

\section{I. Traffic Survey}

3.I.I Stopping time of shuttle bus

Stopping time refers to the total time duration the shuttle bus spends at the bus stop. The stopping time is made up of:

a) The boarding stop time "A": This is also made up of the time taken to close the door = I2 seconds; time taken by the driver to check the traffic before take-off $=5$ seconds; and time taken to park the bus and open the bus for commuters $=5$ seconds.

$\mathrm{A}=(\mathrm{I} 2+5+5)=22$ seconds

b) The average boarding time per passenger $=$ " $\mathrm{BI}_{\mathrm{I}}$ " $=\mathrm{I} 7$ seconds

c) Number of passengers boarding $=\mathrm{n}_{\mathrm{I}}=18$ passengers. 
Mathematically, stopping time $\mathrm{T}=\mathrm{A}+\mathrm{B}_{1} \mathrm{nI}_{\mathrm{I}}$

Stopping Time $=\left(22+\left(17^{\star} 18\right)\right)=(22+306)=328$ seconds

Stopping Time $=5.47$ minutes

\subsection{Waiting Time}

This is the length of time spent by the passengers at the bus stop before boarding a bus. It is also referred to as Delay. The queuing theory is employed in this study.

a) Average arrival rate $(\lambda)=226$ passengers/hour

$\lambda=\frac{226}{3600}=0.0628$

b) Average service rate $(\mu)=243$ passengers $/$ hour

$\mu=\frac{243}{3600}=0.0675$

c) Average interval between arrival $=\frac{1}{\lambda}$

$=\frac{1}{0.0628}=15.924$ Seconds

d) Average interval between service rate $=\frac{1}{\mu}$

$=\frac{1}{0.0675}=\mathrm{I} 4.8 \mathrm{I} 5$ Seconds

e) Average queue length $=\frac{\lambda^{2}}{\mu(\mu-\lambda)}$

$=\frac{0.0628^{2}}{0.0675(0.0675-0.0628)}==\frac{0.0039}{0.00032}=12.19$ Passengers

f) Average waiting time in the queue $=\frac{\lambda}{\mu(\mu-\lambda)}$

$=\frac{0.0628}{0.0675(0.0675-0.0628)}==\frac{0.0628}{0.00032}=196.25$ Seconds $=3.27$ Minutes

g) Average time spent in the system (bus stop) $=\frac{1}{\mu-\lambda}$

$=\frac{1}{0.0675-0.0628}=212.76$ Seconds $=3.55$ Minutes

h) Efficiency of shuttle bus operation based on bus stop utilization $(\mathrm{R})=\frac{\lambda}{\mu}$

$\mathrm{R}=\frac{0.0628}{0.0675}=0.93$

It is important to note that the Utilization factor is less than $\mathrm{I}(\mathrm{R}<\mathrm{I})$, hence the performance of University transport bus shuttle is 93 percent which indicates a very good performance such that the supply of shuttle bus in FUTA is capable of meeting the demand.

\section{Conclusion and Recommendation}

This study has examined the performance of University transport bus shuttle based on utilization using a Single-server queue system which occur if arrival and service rate is Poisson distributed (single queue) (M/M/I) queue. It is concluded that the performance of University transport bus shuttle is 93 percent which indicates a very good performance such that the supply of shuttle bus in FUTA is capable of meeting the demand. This result is very close to that of Sidiq (2019) which finds that the performance of University transport bus shuttle is 96.6 percent. This study can be improved upon by examining the peak and off-peak period of traffic in the two major corridors (North gate and South gate) of FUTA, the economic cost of operating bus shuttle services can also be examined.

\section{References}

Adan, I., and Resing, J. (2015). Queuing Systems. Department of Mathematics and Computer Science, Eindhoven University of Technology, Netherlands, 2015.

Adanikin, A., Olutaiwo, A., and Obafemi, T. (20I7). Performance Study of University of Ado Ekiti (UNAD) Transit Shuttle Buses. American Journal of Traffic and Transportation Engineering, 2(5): 67-73 doi: I0.I I648/j.ajtte.20170205.I2.

Ademoh, N. A., and Anosike, E. N. (2014). Queuing Modelling of Air Transport Passengers of Nnamdi Azikiwe International Airport Abuja, Nigeria Using Multi Server Approach. Middle East Journal of Scientific Research 2I (12): 2326-2338, 20 I4 doi: I0.5829/idosi.mejsr.20I4.2I.I2.2I 807.

Adeniran, A. O., and Kanyio, O. A. (2019). Quantitative Model of Single-Server Queue System. Indian Journal of Engineering, I6, I77-I83.

Aderamo, A. J. (2012). Urban transportation problems and challenges in Nigeria: A planner's view. Prime Journals. 2(3), I98203. 
Bastani P. (2009). A Queuing Model of Hospital Congestion. MSc. Thesis submitted to Department of Mathematics Simon Fraser University

Copper, R. B. (198I). Introduction to Queuing Theory, $2^{\text {nd }}$ Edition North Holland.

Gross, D., and Harris, C. M. (1985). Fundamentals of Queuing Theory, $2^{\text {nd }}$ ed. John Wiley \& Sons: New York.

Jain, J. L., Mohanty, S. G., and Bohm, W. (2007). A Course on Queuing Models, Statistics. A series of Textbooks and Monographs, Chapman \& Hall/CRC, Taylor \& Francis Group.

Sidiq, O. Ben. (2019). Single-Server Queue System of Shuttle Bus Performance: Federal University of Technology Akure as Case Study. American International Journal of Multidisciplinary Scientific Research, 5(3), 9-I4

Sztrik, J. (2012). Basic Queuing Theory. University of Debrecen, Faculty of Informatics.

Trani, A., A. (201I). Introduction to Transportation Engineering, Introduction to Queuing Theory. Virginia Polytechnic Institute and State University, US, Pp: 2-46.

\section{Copyrights}

Copyright for this article is retained by the author(s), with first publication rights granted to the journal. This is an open-access article distributed under the terms and conditions of the Creative Commons Attribution license (http://creativecommons.org/licenses/by/4.0/). 